\title{
A TEORIA DISCURSIVA DO DIREITO DE JÜRGEN HABERMAS
}

\author{
The discursive theory of Law by Jürgen Habermas
}

\section{Carlos Rogério Guedes Pires}

Procurador Municipal de Porto Alegre (RS, Brasil). Graduado em Ciências Jurídicas e Sociais UFSM. Especialização em Direito Municipal ESDM/FMP. Mestre em Sociologia UFRGS.

\section{Resumo}

O presente artigo é um esforço de exposição da teoria discursiva do direito de Jürgen Habermas, compreendida como um empreendimento teórico de fundamentação do estado democrático de direito e da ideia de co-originariedade e implicação necessária entre direito e democracia. Ao investigar a tese weberiana da legitimação racional-legal com o objeto de compreender / desvelar a legitimidade que decorre da legalidade, Habermas, utilizando-se dos meios da tereia da ação comunicativa, reconstrói por meio do princípio do discurso e da forma do direito, os fundamentos dos sistemas dos direitos e dos princípios do estado democrático de direito, para concluir que em sociedades complexas e plurais, o processo democrático de formação da opinião e da vontade sustenta toda a carga de legitimação do direito.

Palavras-chave: Habermas. Ação comunicativa. Direito, democracia e estado democrático de direito.

\section{Abstract}

The present paper is an effort to expose the discursive theory of Law by Jürgen Habermas, understood as a theoretic undertaking of ground democratic constitutional state and the thesis of co-originality and necessary implication between Law and democracy. When investigating the Weberian thesis of rational-legal legitimation with the object of understanding / unveiling the legitimacy that stems from legality, Habermas, using the means of the theory of communicative action, reconstructs through the principle of discourse and the form of law, the foundations of the systems of rights and the principles of the democratic constitutional state, to conclude that in complex and plural societies, the democratic process of opinion and will formation sustains the entire burden of legitimizing Law.

Keywords: Habermas. Communicative action. Law, democracy and democratic state.

\section{Sumário}

1. Introdução; 2. Ação e racionalidade comunicativa; 3. Direito e Democracia; 4. A transformação de poder comunicativo em poder administrativo; 5. Circulação do poder: do poder comunicativo ao poder administrativo; 6. Notas; Referências. 


\section{INTRODUÇÃO}

O objetivo do presente trabalho é apresentar a teoria do direito do filósofo e intelectual público alemão Jürgen Habermas, em especial o trabalho Direito e Democracia, publicado em 1992. Pese o tempo transcorrido desde a sua publicação, uma aproximação da obra no presente contexto parece adequada.

A ideia de que o estado de direito necessita do qualificativo de democrático é relativamente recente. Apenas após a segunda guerra mundial e a conscientização sobre os horrores do nazismo e do stalinismo parece ter se formado no ocidente europeu e nos Estados Unidos, sob a liderança deste último, um certo consenso em torno do regime democrático. A teoria do direito mais influente do período era o positivismo jurídico (KELSEN), que não se propõe problema da formação do direito e para o qual, em princípio, o direito poderia caracterizar-se como tal, independentemente do processo de sua criação.

A retomada de um texto que no próximo ano (2022) completa 30 anos se justificaria simplesmente em razão da sua importância e da repercussão crítica que gerou. Mas para além disso, no presente contexto, quando ascendem discursos que se opõem à democracia, tanto no âmbito nacional como internacional, supondo a viabilidade de um estado de direito sem democracia, parece importante voltar a um autor para quem levar os direitos a sério implica, necessariamente, levar a sério a democracia.

Nesse sentido, o presente trabalho compreende o trabalho de 1992, como a fundamentação, a partir da teoria social desenvolvida na Teoria da Ação Comunicativa, da imbricação conceitual e dependência recíproca entre direito e democracia: a tese da co-originariedade entre a forma jurídica e o processo democrático de criação do direito.

Tal empreendimento alimenta-se da ideia de que compreender os fundamentos do estado democrático de direito permite explicitar, ao mesmo tempo, as limitações dos discursos que pretendem que o estado de direito possa prescindir da democracia.

O direito sempre jogou um papel destacado na teoria social de Jürgen Habermas. Desde sua investigação sobre a esfera pública burguesa no início dos anos sessenta do século passado até sua obra magna de 1981, A Teoria da Ação Comunicativa (daqui em diante TAC, iniciais da versão espanhola). Apenas no final dos anos oitenta e início dos noventa, no entanto, Habermas dedica dois trabalhos sistemáticos ao direito. As Tanner Lectures on Human Values de 1986, intitulada Direito e Moral e o trabalho de 1992, Direito e Democracia (daqui em diante BFN, iniciais da versão em inglês). Como Habermas refere na apresentação das Tanner Lectures, sua intenção ao investigar o direito, embora de caráter normativo, não pretende desenvolver uma teoria do direito, mas uma teoria social. Em Direito e Democracia Habermas ainda persegue uma teoria da sociedade e o papel do direito na integração de sociedades que se tornaram altamente complexas e atravessadas pelo pluralismo de visões de mundo e modos de vida. Porém, nesse trabalho o autor se enfrenta com questões que se referem diretamente à teoria do direito, propriamente, em especial ao papel da jurisdição, que representa o ponto de convergência da abordagem contemporânea sobre o direito (onde se destacam os trabalhos de Dworkin e Alexy). 
Se a Teoria da Ação Comunicativa pode ser lida como uma tentativa de responder ao problema hobbesiano da ordem (PARSONS, 1949, p. 89 e ss.), vale dizer, como é possível que uma sociedade de indivíduos orientados para o próprio êxito possa vir a se reproduzir e estabilizar, Direito e Democracia representa o desdobramento jurídico, político e institucional desse projeto (REHG, 1996; NOBRE; REPA, 2012, p. 39-40), onde o direito aparece como o medium através do qual formas de comunicação improváveis se institucionalizam para estabilizar expectativas de comportamento de modo legítimo (BFN, p. 17). Como sublinha Parsons, "uma ordem social é sempre uma ordem factual na medida em que é suscetível de análise científica, mas é um tipo de ordem que não pode estabilizar-se sem o efetivo funcionamento de certos elementos normativos"1 (PARSONS, 1949, p. 92). Nesse sentido, a investigação levada a cabo em Direito e Democracia diz respeito às bases normativas da legitimidade que surge da legalidade. A questão é levantada a partir de uma discussão com Max Weber e constitui o tema central das Tanner Lectures de 1986.

Pretendo, assim, apresentar o que penso serem os pontos centrais da obra de 1992 para a explicação das bases normativas do direito e que suportam a explicação habermasiana da legitimidade, centrado, em especial nos capítulos III e IV de Direito e Democracia e que tratam, respectivamente, do sistema dos direitos e dos princípios do estado democrático de direito. Antes, porém, e na medida em que Direito e Democracia pode ser compreendido como o desdobramento institucional da TAC, convém assentar os parti pris conceituais que informam a obra. Assim, primeiro, apresento os conceitos de ação e racionalidade comunicativas e seu conceito complementar de mundo da vida; em seguida pretendo apresentar a reconstrução do sistema de direitos e dos princípios do estado de direito. Por fim, as consequências que Habermas retira para uma compreensão procedimental do direito e das possibilidades emancipatórias em sociedades complexas e pluralistas.

\section{AÇÃO E RACIONALIDADE COMUNICATIVA}

Em Direito e Democracia Habermas parte do aparato conceitual construído na Teoria da Ação Comunicativa para explicar o surgimento do direito moderno e sua institucionalização nas formas do estado constitucional. Trata-se de reconstruir a racionalidade imanente à integração social a partir do núcleo que representa a interação entre duas pessoas que visam entender-se sobre algo com base em razões. Essa reconstrução é levada a cabo através de uma reconstrução da história da teoria social (REPA, 2012), com a qual Habermas procura comprovar a intuição que funda sua teoria da comunicação. Segundo McCarthy (1994),

the basic moral intuitions the theorist reconstructs are, as Aristotle noted, aquired in the process of socialization; but, Habermas argues, they include an "abstract core" that is not culture- but species-specific. Members of our species become individuals in and trough being socialized in networks of reciprocal social relations, so that personal identity is from that start interwoven with relations of mutual recognition.

A reconstrução da história da teoria social visa a comprovação por via indireta dos insights obtidos através da teoria da linguagem e se desenvolvem ao longo de toda a obra de 1981 em extensas discussões críticas com Weber, Durkheim, Mead, passando pela tradição do marxismo ocidental da Teoria Crítica de Horkheimer e Adorno, até Parsons. Não discutirei 
este ponto, mas é importante apontar seu papel na reconstrução da teoria social de Habermas como um todo. Para as finalidades do presente trabalho, todavia, basta a apresentação sumária dos conceitos de ação e racionalidade adquiridos através da virada linguística. Suportam o esforço reconstrutivo, principalmente, os achados da filosofia da linguagem, a chamada virada linguística, especialmente na tradição de Austin e Searle. Desenvolvendo a partir da teoria dos atos de fala de Austin, Habermas elabora o conceito de ação comunicativa. A ideia central colhida de Austin, de que os atos de fala não servem apenas a propósitos cognitivos (comunicar uma informação), mas também envolvem a oferta de um vinculo eficaz na coordenação da ação de, ao menos, dois atores, se reconstrói a intuição, em alguma medida efetiva na prática comunicativa cotidiana, de que é possível a ação orientada para o entendimento recíproco. Segundo a teoria dos atos de fala de Austin, os atos de fala regulativos (o exemplo paradigmático é aquele de fazer uma promessa) são compostos por dois elementos, um conteúdo proposicional, no sentido semântico (uma descrição de um estado de coisas), e uma força ilocucionária, ${ }^{2}$ uma oferta do falante ao ouvinte para vincular-se a ela com um sim ou um não. Por exemplo: se A promete a $B$ visitá-lo no dia seguinte, o dia e hora, o local do evento e o próprio conceito de visita representam o conteúdo semântico da proposta, elementos passíveis de constatação conforme o estado de conhecimento dos envolvidos; a promessa, propriamente, representa essa oferta de estabelecimento de um vínculo entre $A$ e $B$ que irá orientar ambos em seus comportamentos subsequentes. Habermas, seguindo John Searle, generaliza a proposição de Austin para sustentar que todo ato de fala, e não apenas os regulativos (eu prometo, declaro, etc.), contêm uma força ilocucionária, criadora de vínculo entre falante e ouvinte e, portanto, capaz de coordenar ações com base no entendimento (EDGAR, 2006, p. 72).

Ao buscar entender-se com alguém sobre algo no mundo, os atores se engajam em um processo de negociação de sentido a fim de estabelecer uma definição comum da situação da ação e empreender ações coordenadas (TAC I, p. 145). Esse processo, no entanto, somente pode ser conduzido à base de um conjunto de idealizações que raramente se confirmam na prática. Assumem que atribuem significados idênticos às suas emissões, a sinceridade dos participantes na interação, a orientação por pretensões de validade criticáveis e condições de discussão que preservam a liberdade e a igualdade. Nas palavras de Habermas (2000, p.140), "ninguém pode entrar seriamente em uma argumentação se não pressupõe uma situação conversacional que garanta em princípio a publicidade do acesso, a participação com igualdade de direitos, a veracidade dos participantes, a ausência de coação na hora de tomar postura, etc." Idealizações que podem se vir frustradas no transcurso da interação e estão sempre sujeitas ao sim ou não do (s) ouvinte (s). A rejeição de um proferimento, por sua vez, pode conduzir o falante a esclarecer o conteúdo de sua emissão, apresentar evidência para os estados de coisa explicitados ou supostos, apresentar justificativas em relação ao seu direito de proferir aquela emissão, etc. Assim, a realização de um ato de fala, e, já aqui, uma ação comunicativa, envolve, com sua oferta de vínculo, uma garantia antecipada de que, apresentando-se o caso, o falante pode aduzir razões adicionais em favor de suas emissões, o que torna possíveis, ao mesmo tempo, acordos racionalmente motivados e processos de aprendizagem. A partir dos conceitos de ação social correntes em sociologia, Habermas propõe (TAC I, p. 143-6), então, um conceito de ação comunicativa 
que permite compreender como falantes competentes de uma língua entendem-se sobre algo no mundo com base em razões. Os atores referem seus proferimentos a um marco de referência formado por três conceitos formais de mundo: um mundo objetivo formado pelo conjunto de entidades passíveis de enunciados verdadeiros, um mundo social como conjunto das relações interpessoais legitimamente reguladas e um mundo subjetivo como conjunto das vivências do falante, as quais ele tem um acesso privilegiado (TAC I, p. 121-2). A ação comunicativa reconstrói a forma como os falantes estabelecem as relações entre seus enunciados e esse marco de referência através de pretensões de verdade, de correção normativa e de sinceridade a respeito das próprias vivências e sentimentos (TAC I, p. 79). O dissenso ocorrido no âmbito das interações cotidianas pode ser "resgatado" através de discursos. Nesse plano, que não é o plano da ação, os atores buscam justificar, em atitude hipotética (colocando em suspenso a validade das pretensões controvertidas), uma definição comum da situação que se tornou problemática no âmbito da ação. Justamente a orientação da ação por pretensões de validade inscrita na própria estrutura da linguagem e o sistema de referência dos três mundos é que permite, no âmbito do discurso, o desenvolvimento de um saber especializado em questões de verdade (ciência), justiça (direito e moral) e gosto (arte e a crítica da arte) (TAC I, p. 36-8).

Esse conceito de ação comunicativa Habermas opõe ao conceito de ação estratégi$\mathrm{ca}^{3}{ }^{3}$ onde os atores tomam uns aos outros como meios $\mathrm{p}$ anente ao uso da linguagem e, assim, conceber processos de integração social que podem ser conduzidos racionalmente pelos envolvidos, onde a única coerção admitida é a coerção fraca representada pelo melhor argumento:

\begin{abstract}
Los participantes en la argumentación tienen todos que presuponer que la estructura de su comunicación, en virtud de propiedades que pueden describirse de modo puramente formal, excluye toda otra coacción, ya provenga de fuera de ese proceso de argumentación, ya nazca de ese proceso mismo, que no sea la del mejor argumento (con lo cual queda neutralizado todo otro motivo que no sea el de la búsqueda cooperativa de la verdad). Bajo este aspecto la argumentación puede entenderse como una continuación con otros medios, ahora de tipo reflexivo, de la acción orientada al entendimiento (TAC I, p. 46).
\end{abstract}

Claro está que uma integração que dependa a cada instante dos esforços de entendimento dos próprios atores assenta em bases frágeis, sempre sujeitas ao risco de dissenso. A estabilidade de processos de entendimento somente se efetiva porque a ação comunicativa transcorre sob um pano de fundo de certezas autoevidentes. A esse pano de fundo Habermas designa como "mundo da vida", na esteira da fenomenologia filosófica de Husserl e da sociologia do conhecimento de Schutz. Ao contrário desses autores, no entanto, busca especificar suas diferenciações com o fito de evitar o viés culturalista da fenomenologia filosófica. Assim, as diferenciações estruturais do mundo da vida reproduzem estoques de saber que alimentam as interações cotidianas nos seguintes níveis: cultura (acervo de saber, nos quais os participantes na comunicação se abastecem de interpretações para se entender sobre algo no mundo), sociedade (as ordenações legítimas através das quais os participantes na interação regulam seus pertencimentos e asseguram a solidariedade) e personalidade (as competências que convertem um sujeito em alguém capaz de linguagem e ação capacitando-o para tomar parte em processos de entendimento e para afirmar sua própria identidade) (TAC II, p. 169-214). Segundo Habermas, a reprodução desse acervo 
depende de modo crescente, em face da perda das garantias sagradas das ordens sociais, de processos de entendimento com meios discursivos, através da reprodução cultural, da integração social e da socialização (TAC II, p. 200-1). Esses processos se referem todos a reprodução simbólica do mundo da vida, ou seja, a reserva de sentido de atores socializados comunicativamente. A sociedade, por outro lado, deve também dar conta de sua reprodução material. Com a evolução social esses processos se racionalizam, no sentido de perderem suas garantias sagradas e metafísicas, e a integração social cobra, cada vez mais, os esforços comunicativos de atores orientados pelo entendimento (REPA, 2012, p. 63). Com isso eleva-se também o risco de dissenso e, portanto, a geração de crises (TAC II, p. 203, fig. 22). As quais só podem ser superadas pela imunização contra a crítica ou através de processos de argumentação que sobrecarregam os atores. É nesse sentido que os mecanismos de reprodução material que recorrem a meios não simbólicos de coordenação da ação são reconhecidos como ganhos evolutivos (TAC II, p. 480) que descarregam os atores do ônus de entender-se com base na ação comunicativa, ou seja, pelo entendimento sobre a base de pretensões de validade criticáveis. Com o conceito parsoniano de meios de direção (steering media) Habermas explica a formação de sistemas de ação que discorrem independentemente da ação orientada ao entendimento e permitem aos atores, nesses âmbitos, orientarem-se exclusivamente para o próprio êxito, vale dizer, estrategicamente (TAC II, p. 217). O exemplo paradigmático é o dinheiro. A famosa imagem da "mão invisível" de Adam Smith. O papel do dinheiro na facilitação de processos de reprodução material é apresentado de forma cômica no filme de curta-metragem Ilha das Flores, de Jorge Furtado, ao ilustrar as dificuldades de um sistema de escambo quando visa a troca de baleias por galinhas. O dinheiro resolve, justamente, esse problema das trocas entre grandezas não equivalentes e a dificuldade ou custo de tratar esse problema discursivamente a cada vez que a situação se apresenta.

Para Habermas, o mercado e o aparato burocrático estatal representam os dois sistemas que, na modernidade, se especializam nas funções de troca e de tomada de decisões vinculantes, respectivamente, que transcorrem de forma independente do entendimento (TAC II, p. 377 e ss.): o dinheiro, no caso do mercado, e o poder institucionalizado no sistema de cargos da administração estatal (BAXTER, 2011). Ambos, todavia, para institucionalizar-se devem estar ancorados no mundo da vida dos atores através do direito privado e do direito público (TAC II, p. 387). Para Habermas, embora representem, ambos, ganhos evolutivos na resolução de problemas de integração social, seu desenvolvimento autonomizado e orientado para sua própria reprodução pode vir a interferir, e essa é a tese de Habermas, na reprodução simbólica de esferas sociais que só podem se integrar através de mecanismos de entendimento, gerando, assim, sintomas patológicos de perda de sentido, perda de liberdade e psicopatologias (TAC II, p. 432). Na TAC o direito aparece como o meio através do qual os imperativos de reprodução dos sistemas mercado e administração estatal invadem esferas da vida cotidiana, "colonizando-a" (TAC II, p. 502 e ss.). Habermas designa esses processos de processos de juridificação, quando o direito se desenvolve expandindo sua forma de regulação para novas esferas sociais e densificando a regulação de esferas já reguladas. São justamente as formas de regulação do estado de bem-estar (monetarização e burocratização) que Habermas identifica como ambíguas. Ao mesmo tempo em que visam 
o atendimento de necessidades sociais, em especial a correção de disfunções da economia capitalista, sua forma de intervenção sobre a vida cotidiana dos indivíduos produz processos de sujeição normalizadora, no sentido de Foucault.

Em resumo, podemos compreender a racionalidade comunicativa como a forma de integração social que transcorre a partir da interação de atores que se orientam por pretensões de validade criticáveis a fim de estabelecer acordos sobre a sua situação comum e coordenação da ação subsequente. Essa racionalidade é formadora de consensos que institucionalizam processos de reprodução cultural formando um acervo de saber compartiIhado, processos de reprodução social formador de ordenações legitimamente reguladas e processos de socialização que capacitam as novas gerações para a atuação competente. Esses mesmos processos formam mecanismos de reprodução material que transcorrem em grande medida independentemente da intenção dos atores e se reproduzem a partir da ação estratégica. Como refere Peters (1996), as distinções entre sistema e mundo da vida e as formas correlatas de ação, estratégica e comunicativa, devem ser pensadas mais como tipos ideais, no sentido de Max Weber, uma vez que nos processos reais podem apresentar-se cruzamentos e sobreposições. O diagnóstico de época de Habermas na TAC, em todo o caso, presume que essas distinções tem uma força descritiva, uma vez que identifica como problema a "colonização do mundo da vida" por imperativos sistêmicos e propõe como solução o levantamento de barreiras e a delimitação das fronteiras (TAC II, p. 558-62). Ao concluir o trabalho de 1981, Habermas anuncia que a viabilidade do programa de pesquisa delineado deve ser testada em face das ciências empíricas que tomem a reconstrução das competências linguísticas de atores orientados ao entendimento como input para reconstruções de objetos específicos como, por exemplo, "a evolução de sistemas jurídicos". Também por essa razão se justifica tomar a pesquisa desenvolvida em Direito e Democracia como o emprego da TAC ao fenômeno jurídico e, também, a apresentação, em traços muito amplos, dos principais elementos da TAC que são preliminares à abordagem do trabalho de 1992.

\section{DIREITO E DEMOCRACIA}

É interessante iniciar pelo título. O título alemão da obra de Habermas dedicada ao estudo do fenômeno jurídico é faktizität und Geltung, mantido na versão castelhana (Facticidad y Validez) e, com um sentido já interpretativo, na versão para o inglês (Between Facts and Norms). Para Habermas, o direito partilha com a linguagem de uma tensão imanente entre a facticidade social (que não se confunde com o plano dos fatos como induz a tradução estadunidense) e a idealidade das pretensões de validade que são sempre proferidas aqui e agora, mas pretendem validade (verdade, correção e sinceridade) transcendente ao espaço social e ao tempo histórico, uma tensão entre contexto e idealidade (COELHO, 2014). De outro lado, à questão "como é possível a legitimidade a partir da legalidade?" (HABERMAS, 1997 e 2001), Habermas responde com a imbricação conceitualmente necessária entre direito e democracia, o que, de certa forma, justifica o título da tradução ao português. O subtítulo da publicação alemã, "Beiträge zur Diskurstheorie des Rechts und des Demokratischen Rechtsstaats", numa tradução livre, indica que a obra se trata de uma contribuição para uma teoria discursiva do direito e do estado democrático de direito, no que remete à reconstrução em termos de teoria do discurso dos direitos e dos princípios do estado de direito desen- 
volvida nos capítulos III e IV. Nessa relação entre os direitos e o processo democrático de sua criação se expressa o aspecto central da tensão interna entre faticidade e validade, a concorrência entre direitos humanos e soberania popular, de um lado, e entre exercício do poder político estatal e sua autorização democrática, por outro. A teoria discursiva do direito pretende, exatamente, mostrar como essa concorrência é absorvida e operacionalizada no direito moderno estabilizando processos de integração social premidos pelo risco de dissenso em sociedades marcadas pela crescente complexidade social e pluralização de visões de mundo e modos de vida.

Hence, the concept of modern law, which both intensifies and behaviorally operationalizes the tension between facticity and validity, already harbors the democratic idea developed by Rousseau and Kant: the claim to legitimacy on the part of a legal order built on rights can be redeemed only through the socially integrative force of the "concurring and united will of all" free and equal citizens (BFN, p. 33).

Habermas parte da constatação da existência de duas perspectivas contrastantes sobre o direito moderno, a perspectiva da teoria de sistemas, que vê no direito um subsistema entre outros que se reproduz autonomamente a partir de sua própria lógica (código) interna, estabilizando-se em face de outros subsistemas que lhe servem de contexto; e a perspectiva da teoria da justiça, que pretende fundar princípios de justiça através de uma argumentação diretamente normativa. Para Habermas as duas perspectivas padecem de uma leitura seletiva do direito, a primeira pela cegueira normativa, a segunda pela perda de contato com a realidade complexa das sociedades contemporâneas (BFN, p. 66). Sua meta, então, é conciliar a autoimagem do direito moderno com os processos empíricos de circulação do poder em sociedades complexas e pluralistas a partir de sua teoria do discurso. O diagnóstico resultante sustenta a degeneração dos paradigmas liberal e do estado social, que informam os atores do sistema jurídico e também os cidadãos, em leituras incapazes de reconhecer o papel do processo democrático na legitimação do estado constitucional e democrático de direito (BFN, p. 407-8). A superação dessa crise estaria dada pelo paradigma procedimental, já em curso, e capaz de articular a institucionalização de processos discursivos de formação do direito legítimo e, portanto, a capacidade da sociedade de atuar sobre si mesma (BFN, p. 409).

Assim como na TAC, Habermas pretende uma reconstrução racional, essa vez da autocompreensão do direito moderno, aproveitando-se dos ganhos teóricos com a reconstrução da ação comunicativa. Segundo o autor, reconstrução racional é um modo de proceder teórico que tem por "objetivo dar conta do saber pré-teórico e do domínio intuitivo de sistemas de regras que estão na base da geração e avaliação de proferimentos e operações simbólicos" (HABERMAS, 2003, p. 48). Proceder que alimenta a pretensão de que, "na medida em que as reconstruções racionais explicitam as condições de validade de proferimentos, elas também podem explicar casos desviantes e assim adquirir também, com essa autoridade indiretamente legisladora, uma função crítica" (HABERMAS, 2003, p. 48). Nesse sentido, a reconstrução como mecanismo de produção de saber válido e, portanto, capaz de desempenhar uma "função crítica", parte da compreensão que os próprios atores têm de suas práticas e as avalia desde a perspectiva interna de um participante. Com isso, "os intérpretes perdem, é verdade, o privilégio do observador não participante ou da terceira 
pessoa, mas pela mesma razão, dispõem dos meios para manter de pé, desde dentro, uma posição de imparcialidade negociada" (HABERMAS, 2003, p. 46). A capacidade explicativa da reconstrução é "testada" na confrontação com as práticas das quais procura justificar os pressupostos racionais. De modo que, "Discourse theory explains the legitimacy of law by means of procedures and communicative presuppositions that, once they are legally institutionalized, ground the supposition that the processes of making and applying law lead to rational outcomes". (BFN, p. 414)

No capítulo III de Direito e Democracia Habermas desenvolve sua reconstrução do sistema dos direitos em diálogo com as duas tradições que representam a doutrina do direito privado alemão e as teorias do contrato social. Segundo suas conclusões, ambas falham em compreender a relação entre direitos e democracia ou, em sentido mais técnico, entre a autonomia privada dos indivíduos e a autonomia pública dos cidadãos (BFN, p. 84-94). As doutrinas do direito privado alemão centradas no conceito de direitos subjetivos, seja na versão idealista de Savigny, que os fundava na inviolabilidade pessoal e, portanto, com uma legitimidade prévia ao processo de legislação, seja na versão positivista derivada de Kelsen que os reduzia a mera atribuição do direito objetivo (lei estatal) o qual era tomado como pura dominação legal, perdem de vista a conexão entre a autonomia privada garantida pelos direitos e a autonomia pública através da qual os cidadãos podem se compreender como autores do direito (HABERMAS, 1997, p. 116-22). As teorias do contrato social, por sua vez, nas versões de Kant e Rousseau intuem a relação de implicação recíproca entre direitos humanos e soberania popular, mas a articulam de modo parcial. Em Kant os direitos derivam diretamente da moral através do imperativo categórico submetendo o legislador político as suas prescrições, enquanto em Rousseau é a vontade geral, ancorada no "povo" concebido como um macrossujeito capaz de compreensão e ação, e confiada na forma semântica de normas gerais e abstratas, que se sobrepõe aos direitos humanos. As duas leituras do direito, segundo Habermas, perdem de vista as implicações recíprocas, conceituais, entre direito e democracia.

O objeto do Capítulo III de Direito e Democracia, portanto, é a superação, através da teoria do discurso, da concorrência entre direitos humanos e soberania popular que remontam às tradições de Locke e Aristóteles, respectivamente, e que se expressam contemporaneamente no debate anglo-saxão entre liberais e comunitaristas. Segundo uma versão estilizada dessa disputa, liberais, como Locke, assentam a legitimidade do direito no reconhecimento de direitos naturais preexistentes que devem ser reconhecidos pelo legislador político e que criam uma esfera privada protegida de intervenções arbitrárias do Estado e dos outros indivíduos. Tais direitos (vida, liberdade e propriedade) autorizam uma condução da vida em termos eminentemente individualistas, orientada pela lógica do mercado, enquanto o processo político de elaboração de leis resta constrangido pela manutenção dessa esfera privada excluída do debate público dos cidadãos. O Estado deve ser neutro em relação às concepções de vida boa professadas pelos indivíduos e grupos sociais. $\mathrm{Na}$ perspectiva republicana, por sua vez, são os cidadãos, enquanto autores de um processo de auto-constituição coletiva orientada pelo bem comum que se engajam em um processo deliberativo orientado pela autocompreensão "ética" de um povo. O processo deliberativo, por sua parte, se ampara em um contexto de valores compartilhados que representam a própria 
identidade individual e coletiva da comunidade. As duas liberdades que Benjamin Constant designa como a liberdade dos modernos e a liberdade dos antigos, respectivamente. Como refere Habermas, o risco implicado na perspectiva liberal é o paternalismo dos direitos sobre o processo democrático que restringe a deliberação democrática dos cidadãos. $\mathrm{O}$ risco da perspectiva republicana ou comunitarista, de outro lado, é a imposição autoritária de um modo de vida particular, a busca de pureza cultural, através da supressão de direitos individuais. Assim, paternalismo dos direitos e "ditadura da maioria" representam os riscos extremos dessas leituras parciais do direito, que alimentam uma relação de competição entre os dois fundamentos de legitimidade do direito. Desse modo,

\begin{abstract}
"liberal" traditions conceive human rights as the expression of moral self-determination, whereas "civic republicanism" tends to interpret popular sovereignty as the expression of ethical self-realization. From both perspectives, human rights and popular sovereignty do not so much mutually complement as compete with each other. (BFN, p. 100)
\end{abstract}

Para Habermas, todavia, as duas únicas fontes de legitimação do direito moderno, após a derrocada dos pressupostos religiosos e metafísicos que animaram sua sustentação pré-moderna, são os direitos humanos e a soberania popular (BFN, p. 99). Daí que desde a perspectiva da teoria do discurso deve se alcançar uma reconstrução dessas fontes que permita compreender a pressuposição recíproca entre ambas.

De acordo com Habermas, "[n]othing is given prior to the citizen's practice of self-determination other than the discourse principle, which is built into the conditions of communicative association in general, and the legal medium as such" (BFN, p. 127-8). Assim a reconstrução do sistema de direitos funda-se, por um lado, no princípio do discurso que decorre justamente daquelas condições de socialização comunicativa que os atores acedem intuitivamente (BFN, p. 128); e por outro, na forma do direito (ou forma jurídica) que, como tal, não admite justificação, mas decorre dos processos de aprendizagem decorrentes da evolução social como único mecanismo de integração nas condições pós-metafísicas das sociedades modernas (BFN, p. 154-6). Isso porque "[l]egal norms of this type [direito positivo] make possible highly artificial communities, associations of free and equal legal persons whose integration is based simultaneously on the threat of external sanctions and the supposition of a rationally motivated agreement". (BFN, p. 8)

Assim, ao decidirem regular sua vida comum através dos meios do direito positivo (BFN, p. 125) os atores somente podem recorrer às formas comunicativas de coordenação da ação dadas pelo princípio do discurso e ao direito positivo, com suas características formais de atribuição de direito subjetivos, positividade e coercibilidade (BFN, p. 119). Segundo o princípio do discurso "[j]ust those action norms are valid to which all possibly affected persons could agree as participants in rational discourses" (BFN, p. 107). Para Habermas, o princípio do discurso é posto ainda de forma neutra em relação ao direito e à moral. Isso porque não estão definidos, ainda, os tipos de normas de ação (morais, éticas ou pragmáticas), o círculo dos afetados (um grupo ou comunidade ou o universo dos seres racionais) e os tipos de discurso orientados a resolução racional de pretensões de validade problemáticas. Com o princípio do discurso Habermas pretende explicitar o sentido da legitimidade de normas de ação que dependem de um acordo intersubjetivo entre possíveis afetados. No entanto, sua inespecificidade em relação a normas morais e normas jurídicas visa evitar a 
compreensão dos direitos como estando em uma situação de subordinação à moral (BFN, $p$. 107; REHG, 1996). Para Habermas, direito e moral estão numa relação de complementação funcional, onde o direito compensa uma moral pós-convencional em suas fragilidades cognitivas, motivacionais e organizativas. Segundo o autor, "Moral and legal prescriptions each have different reference groups and regulate different matters" (BFN, 451, pós-escrito). Segundo Habermas (BFN, p. 114-8), uma moral pós-convencional, que não se encontra mais amparada pela religião ou por pressupostos metafísicos (como no direito natural racional) resta cognitivamente indeterminada, motivacionalmente incerta e incapaz de suportar por si mesma as necessidades de cooperação e organização necessárias ao atendimento das condições de implementação de fins coletivos em uma sociedade complexa. Vale explicar: em relação à indeterminação cognitiva da moral o direito alcança a segurança de decisões explícitas e coletivamente vinculantes, seja na fundamentação de normas (legislação), seja na sua aplicação (adjudicação); em relação à incerteza motivacional dos atores, ou seja, sua capacidade de orientar-se por normas morais, mesmo contra seus interesses imediatos, o direito empresta sua imposição sobre o comportamento externo, se necessário através da imposição forçada; por fim, às exigências organizativas decorrentes da implantação de objetivos coletivos como, por exemplo, o enfrentamento da miséria, o direito permite a construção e divisão de trabalho entre estruturas artificiais de ação como são as corporações e as agencias estatais. Desse modo, o direito liga-se aos pressupostos de uma moral pós-convencional de modo funcional, vale dizer, compensando suas deficiências no plano da ação de modo sistêmico. É assim, que na sua imbricação com o direito o princípio do discurso que, como dito acima, é neutro em relação ao direito e à moral, se operacionaliza na forma de um princípio da democracia, segundo o qual "only those statutes may claim legitimacy that can meet with the assent (Zustimmung) of all citizens in a discursive process of legislation that in turn has been legally constituted" (BFN, p. 110). Essa interpenetração entre Princípio do discurso e forma do direito Habermas designa como a "gênese lógica" do sistema de direitos.

\footnotetext{
One begins by applying the discourse principle to the general right to liberties a right constitutive for the legal form as such-and ends by legally institutionalizing the conditions for a discursive exercise of political autonomy. By means of this political autonomy, the private autonomy that was at first abstractly posited can retroactively assume an elaborated legal shape. Hence the principle of democracy can only appear as the heart of a system of rights. The logical genesis of these rights comprises a circular process in which the legal code, or legal form, and the mechanism for producing legitimate law-hence the democratic principle-are co-originally constituted. (BFN, p. 121-2).
}

Assim, para chegar ao sistema dos direitos são necessários o conceito de forma jurídica (ou forma do direito) que permite a estabilização de expectativas de comportamento através da positivação e do recurso à sanção estatal, e o princípio do discurso através do qual a legitimidade do direito pode ser testada (REPA, 2010). Dessa reconstrução Habermas chega a cinco categorias de direitos (BFN, p. 122-3). As três primeiras, que decorrem diretamente da forma jurídica, são os "direitos básicos que resultam da elaboração politicamente autônoma": da maior medida possível de iguais liberdades individuais; do status de membro de uma associação voluntária de parceiros do direito; e da acionabilidade dos direitos e da ampla proteção jurídica. Do princípio do discurso, por sua vez, decorrem os direitos de participação nos processos de formação da opinião e da vontade através dos quais os cidadãos 
exercem sua autonomia pública na formação do sistema de direitos de modo legítimo. Essa quarta categoria é que operacionaliza, de forma reflexiva, a institucionalização dela própria e das categorias anteriores permitindo a interpretação e o desenvolvimento do direito. Por fim, Habermas apresenta uma quinta categoria de direitos, os direitos sociais e a um ambiente ecologicamente sustentável. Essa quinta categoria, no entanto, somente pode ser justificada de modo relativo, uma vez que não é uma decorrência da gênese lógica que articula de forma conceitual os direitos civis e políticos, ou seja, a autonomia privada e pública dos cidadãos. (BFN, p. 122-3). É justificada de forma relativa, ainda, em razão de sua posição possibilitadora do exercício das demais categorias de direitos.

Algumas qualificações são necessárias nesse ponto. Primeiro, o sistema dos direitos assim justificado não prejulga os direitos que os cidadãos devem atribuir-se reciprocamente no processo de constituição da comunidade jurídica. Somente através do exercício de sua autonomia pública podem chegar à interpretação e desenvolvimento do sistema dos direitos proposto pelo teórico de modo complemente "insaturado", vale dizer, carente da interpretação e que somente pode ser elaborado por comunidades jurídicas concretas, "aqui e agora". Os clássicos direitos liberais são, portanto, interpretações históricas desse sistema de direitos (BFN, p. 125-6). Segundo, o caráter reflexivo do princípio do discurso, especificado na forma de um princípio da democracia também deve ser instituído juridicamente. O princípio da democracia, segundo Habermas, é o resultado da aplicação da forma jurídica ao princípio do discurso. Os próprios atores devem institucionalizar juridicamente os pressupostos de uma formação comunicativa da opinião e da vontade políticas (BFN, p. 126-7). Terceiro, por fim, os direitos de participação comungam com os direitos a iguais liberdades a peculiar forma de validade do direito, no sentido de que são condições asseguradoras de processos de formação discursiva da opinião e da vontade, mas não impõem aos atores a obrigação jurídica de agir comunicativamente, i. e., orientados pelo entendimento. Ou seja, os atores não podem ser obrigados a serem livres, para usar a famosa formulação de Rousseau. Mesmo assim, os pressupostos exigentes da legitimação discursiva do direito dependem da iniciativa de uma população acostumada à liberdade (BFN, p. 130). Isso porque o direito libera os atores para adotar duas posturas básicas em relação às normas jurídicas: a atitude objetivante do ator estratégico que vê no direito positivo apenas as restrições factuais que Ihe permitem decidir seu curso de ação em razão das sanções prescritas, ou a atitude performativa do ator que avalia as normas desde a perspectiva de suas pretensões de validade, o que alberga a possibilidade de cumpri-las por respeito ao seu conteúdo normativo. Nas palavras de Habermas,

Either they can consider legal norms merely as commands, in the sense of factual constraints on their personal scope for action, and take a strategic approach to the calculable consequences of possible rule violations; or they can take a performative attitude in which they view norms as valid precepts and comply 'out of respect for the law'. (BFN, p. 448, Postscript).

Como decorrência dessa formulação, autonomia privada e autonomia pública se interpretam reciprocamente. A autonomia privada assegura a independência necessária à formação discursiva da opinião e da vontade na medida em que preserva um espaço de privacidade que funda a liberdade de arbítrio e a liberdade ética (a busca de uma concepção pessoal e coletiva do bem); a autonomia pública, por sua vez interpreta e reelabora o sistema de 
direitos através dos procedimentos juridicamente estabelecidos diante de circunstâncias sociais cambiantes (SILVA, 2008). Para Felipe Gonçalves Silva: "Caso os cidadãos pretendam regular legitimamente suas vidas por meio do direito, a proteção da privacidade não pode ser produzida sem seu devido esclarecimento e convencimento públicos. $\mathrm{E}$, igualmente, as decisões da vontade coletiva não podem suprimir a livre formação da vontade individual" (SILVA, 2008, p. 112). Segundo Habermas, atores que decidem regular suas interações e vida conjunta com as formas do direito positivo encontram a forma jurídica como o único meio a disposição para a condução do processo discursivo de legislação e, com isso, a atribuição recíproca de direitos subjetivos iguais, de sorte que não está à disposição dos atores a linguagem através da qual irão ativar o processo de legislação: "They no longer have a choice about which language they might want to use. Rather, the legal code is given to legal subjects in advance as the only language in which they can express their autonomy" (BFN, p. 126).

A justificação do sistema de direitos é apresentada do ponto vista horizontal, ou seja, qualquer grupo de indivíduos orientados à produção de uma comunidade jurídica nas condições pós-tradicionais de sociedades modernas secularizadas só dispõe do princípio do discurso e da forma jurídica para regular de forma legítima sua vida coletiva. Segundo Habermas:

Minha reconstrução do significado de uma ordem legal legítima inicia com a resolução original que qualquer grupo arbitrário de pessoas deve fazer se quer se constituir como uma comunidade jurídica de membros livres e iguais. Pretendendo regular legitimamente suas vidas através do direito positivo, eles entram em uma prática comum que os permite elaborar uma constituição [...] Assim essa prática depende de antemão de duas condições: do direito positivo como médium de regulações vinculantes e do princípio do discurso como fio condutor para deliberações e tomadas de decisões razoáveis" (Habermas, 1998, p. 405-6).

\section{A TRANSFORMAÇÃO DE PODER COMUNICATIVO EM PODER ADMINISTRATIVO}

Por outro lado, o sistema de direitos pressupõe, conceitualmente, sua institucionalização na forma do Estado. Assim, o sistema dos direitos desde o início se vincula aos mecanismos institucionais e aos princípios de organização e funcionamento do Estado democrático de direito. Enquanto na reconstrução do sistema dos direitos importava a relação entre direito e moral, no sentido de evitar uma interpretação do direito tributária do platonismo que concebia o direito como subordinado a moral, cabendo ao legislador apenas "reconhecer", no plano do direito positivo, direitos morais prévios. A reconstrução dos princípios do Estado democrático do direito, levada a cabo no capítulo IV de Direito e Democracia, implica na reconstrução da relação entre direito e política. A organização vertical dos cidadãos dentro de um Estado (BFN, p. 135). Em especial, se põe a questão: como processos de formação discursiva da opinião e da vontade operam no âmbito do estado programando-o?

If the interpenetration of private and public autonomy brought about in the system of rights is to be rendered permanent, then the process of juridification must not limit itself to the liberty of private persons and the communicative freedom of citizens. It must extend immediately to that political power already presupposed with the medium of law, a power to which the making as well as the enforcing of law owe their binding character. (BFN, p. 132).

A instituição dos direitos subjetivos, por seu turno, que como direitos positivos depen- 
dem da ameaça de sanções e de sua imposição forçada, pressupõe o aparato sancionador do Estado; o direito ao status de membro de uma comunidade política, da mesma forma supõe uma autoridade central encarregada de proteger contra ameaças externas e garantir a ordem interna; os direitos de proteção legal dependem de um judiciário independente encarregado de tomar decisões vinculantes em caso de conflito; por fim, os direitos de comunicação e participação no processo de legislação compreende a existência de corporações legislativas e de um aparato administrativo encarregado de implementar os programas políticos deliberados (BFN, p. 133-4). Como refere Habermas,

\begin{abstract}
In short, the state becomes necessary as a sanctioning, organizing, and executive power because rights must be enforced, because the legal community has need of both a collective self-maintenance and an organized judiciary, and because political will-formation issues in programs that must be implemented. To be sure, these are not just functionally necessary supplements to the system of rights but implications already contained in rights. (BFN, p. 134).
\end{abstract}

Desta forma, "Habermas propõe uma nova formulação dos princípios do Estado de Direito, na perspectiva da teoria do discurso" (ROCHA, 2008, p. 180). Segundo essa nova formulação são os tipos de discursos e suas correlatas formas de argumentação que estruturam uma divisão funcional de poderes que permite compreender a autodeterminação da comunidade jurídica como resultante de uma formação discursiva da vontade que, por sua vez, alimenta a pressuposição de que os resultados assim obtidos são aceitáveis racionalmente. O princípio da soberania popular deve organizar os processos de legislação que transcorrem através da deliberação em torno de questões morais, éticas e pragmáticas, e também negociações fair, em argumentações que, respectivamente, se orientam pelo igual interesse de todos, pela autocompreensão e realização do bem comum de uma determinada comunidade, pela adequação de meios a fins previamente dados, e pela composição de interesses através de procedimentos imparciais, procedimentos que, por sua vez, devem ser fundamentados através de discursos morais. Esse amplo leque de questões e formas de argumentação somente deve estar aberto em toda sua amplitude ao processo de legislação onde, em princípio, todos são participantes (BFN, p. 172).

O segundo princípio diz com a proteção jurídica garantida por um judiciário independente. Segundo Habermas, os discursos práticos se especializam em discursos de fundamentação de normas e discursos de aplicação de normas. Essa distinção fundamenta a separação de competências entre dois poderes de estado. Ao poder judiciário, portanto, correspondem os discursos de aplicação, uma vez que o judiciário dispõe do acesso ao poder administrativo a fim de implementar suas decisões lhe está vedado programar a sua própria atuação, de sorte a legitimidade das decisões judiciais se vincula ao direito preexistente e à obrigação de justificação perante uma esfera pública jurídica a mais ampliada possível (BFN, p. 172). Assim, o princípio do devido processo organiza uma produção de decisões que se encontram, novamente, ante uma tensão interna ao direito, agora no âmbito da jurisdição, a tensão entre segurança jurídica, ou coerência em relação à história institucional dos atos e decisões passados, e a aceitabilidade racional das decisões, ou sua dimensão de Justiça. Essa tensão, entre facticidade e validade, espelha, no âmbito da jurisdição, a tensão entre positividade e legitimidade que funda a própria forma de validade do direito. É nesse sentido, que o judiciário, quanto mais se envolve em decisões que "desenvolvem" o 
sistema dos direitos, mais se onera com deveres de justificação perante uma esfera pública mais alargada. Justamente porque não lhe estão disponíveis todos os tipos de argumentos abertos ao legislador político. Para Habermas, "[q]uanto mais o judiciário tacitamente assume o papel de um legislador concorrente quando desenvolve o direito, mais resolutamente deve ser requisitado a justificar-se, não apenas diante de um público interno de experts, mas também externamente ante o fórum de cidadãos" (Habermas, 1998, p. 428).

Um terceiro princípio é o princípio da legalidade da Administração. A Administração, por excelência, deve implementar programas deliberados em outras esferas e para tanto dispõe do aparato coercitivo do Estado. Razão pela qual à administração, em princípio, somente é dado operar com argumentos de tipo pragmático, uma vez que sua programação deve decorrer, de novo, em princípio, de fins previamente postos pelo legislador político. $\mathrm{Na}$ medida em que se envolve com processos de "desenvolvimento" do direito, entretanto, deve se abrir à participação mais ampla dos cidadãos em procedimentos quase-legislativos ou quase-adjudicativos (BFN, 193). São exemplos dessa abertura os conselhos de cidadãos, as comissões paritárias e as audiências públicas. Em resumo,

\begin{abstract}
From this argumentation-theoretic perspective, the division of powers and responsibilities among authorities that respectively make, apply, and implement laws follows from the distribution of the possibilities for access to different sorts of reasons and to the corresponding forms of communication that determine how these reasons are dealt with. Political legislators alone enjoy unlimited access to normative, pragmatic, and empirical reasons, including those constituted through the results of fair compromises, though they have this access only within the framework of a democratic procedure designed for the justification of norms. The judiciary cannot make whatever use it likes of the reasons packaged in, and linked to, statutes; these same reasons play a different role when the courts, with an eye to the coherence of the legal system as a whole, employ them in a discourse of application aimed at decisions consistent over time. In contrast to the legislature and judiciary, finally, the administration is not permitted to deal with normative reasons in either a constructive or reconstructive manner. The norms fed into the administration bind the pursuit of collective goals to pregiven premises and keep administrative activity within the horizon of purposive rationality. They empower officials to select technologies and strategies only under the proviso that-in contrast to subjects of private lawthey do not follow their own interests or preferences. (BFN, p. 192, grifei).
\end{abstract}

Um quarto princípio é o da separação entre Estado e sociedade, tão caro ao modelo liberal. A riqueza e o poder social formado no seio da sociedade, ao mesmo tempo em que serve de condição possibilitadora da liberdade individual pode restringir a autonomia dos cidadãos (BFN, p. 175). Em especial quando favorecem o acesso privilegiado aos centros de decisão através dos mecanismos descritos pelas teorias neocorporativistas e sistêmicas do processo político.

Seguindo Hanna Arendt, segundo a qual o poder surge entre os homens quando estes agem em conjunto, e desaparece quando estes se dispersam, Habermas propõe uma nova forma de compreender a circulação do poder em sociedades democráticas. Segundo Habermas, "[i]n contrast to Weber, who sees the fundamental phenomenon of power as the probability that in a social relationship one can assert one's own will against opposition, Arendt views power as the potential of a common will formed in noncoercive communication." (BFN, p. 147). Habermas concebe que as instâncias formais de deliberação dependem dos recursos de legitimação que transcorrem no seio de uma sociedade civil independente tanto 
do mercado, como do poder administrativo. Essa esfera pública política informal que tem sua base nas redes de associações civis que, através de suas contribuições e informações, de suas propostas e questionamentos, na forma de um poder gerado comunicativamente, é capaz de dirigir os processos formais de deliberação influenciando a formação da opinião e da vontade política nas esferas formais do sistema político. Dessa forma, o exercício do poder administrativo aparece como poder derivado, gerado comunicativamente, assumindo as funções sancionadoras e organizativas pressupostas pelo sistema de direitos. Com isso se concebe uma divisão de trabalho entre o poder comunicativo e poder administrativo, apenas esse último capaz de implementar o sistema dos direitos em face de sua capacidade de agir (BFN, p. 149-50). É nesse contexto que o direito positivo moderno se apresenta como um "transformador" do poder generativo de normas de uma esfera pública independente em poder administrativo aparelhado com os meios da ação instrumental implementadora de normas e fins coletivos. Isso decorre, exatamente, da posição que ocupa o direito entre sistema e mundo da vida. Assim, diz Habermas, "Law is two things at once: a system of knowledge and a system of action. It is equally possible to understand law as a text, composed of legal propositions and their interpretations, and to view it as an institution, that is, as a complex of normatively regulated action" (BFN, p. 79). É essa característica da forma jurídica, já observada na TAC que agora aparece como o caminho a ser percorrido pela ação comunicativa para gerar "legitimidade através da legalidade". É também o que torna o direito um mecanismo privilegiado de integração em sociedades pós-tradicionais complexas e plurais. Diz Habermas:

This leads me to propose that we view law as the medium through which communicative power is translated into administrative power. For the transformation of communicative power into administrative has the character of an empowerment within the framework of statutory authorization. We can then interpret the idea of the constitutional state in general as the requirement that the administrative system, which is steered through the power code, be tied to the lawmaking communicative power and kept free of illegitimate interventions of social power (i.e., of the factual strength of privileged interests to assert themselves). (BFN, p. 150).

\section{CIRCULAÇÃO DO PODER: DO PODER COMUNICATIVO AO PODER ADMINISTRATIVO}

Daí que a teoria proponha um fluxo de argumentação pública que seria capaz de transformar poder gerado comunicativamente em poder administrativo (políticas executadas pelo estado). Baseado em B Peters, Habermas (BFN, p. 356 e ss.) propõe o seguinte fluxo, que pode ser visualizado a partir de círculos concêntricos onde no centro estariam as instituições do sistema político formal (administração, tribunais, complexos parlamentares e seus complementos, sistema eleitoral, partidos competitivos, etc), logo em seguida, grupos de representação de interesses funcionais típicos das formas de negociação neocorporativas; na periferia, a esfera pública política informal formada por associações da sociedade civil, associações representativas de grupos de interesses, instituições culturais (academias, intelectuais, escritores, etc.), grupos de interesse público (ambientalistas, defensores dos animais, dos consumidores), igrejas e instituições de caridade, que formam uma rede de associações especializadas captar disfunções e reverberá-las a fim de exercer influência em uma esfera pública dominada pelos meios de comunicação de massa; por fim, a esfera privada dos cidadãos onde os problemas são experimentados, primeiramente. 
Assim, o fluxo do poder comunicativo se inicia pela percepção de problemas necessitados de regulação no âmbito da vida privada dos indivíduos; esses problemas são captados, tematizados, condensados em opiniões públicas e dirigidos ao sistema político por uma sociedade civil capaz de perceber as disfunções experimentadas na esfera privada dos indivíduos e especializada em chamar a atenção para os problemas, mobilizando meios de comunicação de massas e exigindo a atuação do sistema político formal na forma de leis, sentenças e políticas públicas; vencidos os filtros ou comportas do sistema político formal e promovidas as regulações exigidas todo processo se reinicia sobre novas bases. Segundo esse esquema, ainda, o sistema político tem duas formas de tratamento de problemas, uma ordinária, normal e rotineira, onde domina a força de inércia do poder social representado pela Administração e pelo poder econômico, e uma forma extraordinária, quando o fluxo comunicacional proveniente da periferia chega a exercer influência sobre o sistema político formal e o modo rotineiro de funcionamento do sistema é rompido. Um exemplo claro é o processo constituinte brasileiro do final dos anos 80 , quando uma sociedade civil altamente mobilizada e organizada em torno de problemas específicos (urbanistas, sanitaristas, indígenas, quilombolas, etc.) conseguiu influenciar a opinião pública em torno de diversos temas que restaram regulados pela Constituição de 1988.

A partir daí é possível abordar espaços concretos de deliberação e confrontá-los com o modelo ideal. Segundo Habermas,

Discourse theory provides conceptual tools that allow us both to analyze the observable communication flows according to the different issues and to reconstruct them in terms of the corresponding forms of communication [...] the rational reconstruction of a given sequence of communication with discourse-theoretic means allows one to identify deviations that have their source in effects of social and administrative power that cannot be publicly advocated (BFN, p. 285).

Um ponto que não pode deixar de ser constatado é que Habermas trabalha com uma idealização da situação de comunicação, o discurso. Segundo Coelho (2013) essa idealização tem duas funções: uma função cognitiva, pois pretende ser uma reconstrução (real, efetivamente operante) das condições da comunicação a partir da ideia intuitiva de que aqueles que entram em uma argumentação aceitam determinados pressupostos de forma necessária. Nas palavras de Habermas (2000, p. 140), "ninguém pode entrar seriamente em uma argumentação se não pressupõe uma situação conversacional que garanta em princípio a publicidade do acesso, a participação com igualdade de direitos, a veracidade dos participantes, a ausência de coação na hora de tomar postura, etc.". E tem uma função avaliativa ou normativa (crítica), no sentido de que serve de critério de julgamento das argumentações realmente existentes. Nessa segunda função a idealização serve como uma ideia reguladora, pois os discursos reais sempre se afastarão, em alguma medida, do ideal, mas a idealização permite criticar os desvios mais graves (COELHO, 2013).

É desse modo, pela interdependência conceitual entre direitos humanos e soberania popular, pela justificação discursivas dos princípios do estado democrático de direito e pela compreensão dos fluxos comunicacionais que funcionam como condições possibilitadoras da transformação de poder comunicativo em poder administrativo, que conduz Habermas a concluir que em sociedades complexas, pluralistas e que já não podem contar com garantias religiosas e metafísicas, o processo democrático suporta toda a carga de legitimação do 
direito (BFN, p. 450, Postscript).

A legitimidade do direito se alimenta, portanto, dos processos informais de comunicação que circulam na sociedade e, em última instância, provêm das vivências de pessoas socializadas comunicativamente e que não podem ser gerados artificialmente, quer pelo poder administrativo, quer pelo poder social estabelecido.

\section{NOTAS}

1. Tradução livre: "a social order is always a factual order in so far as it is susceptible of scientific analysis but, as will be later maintained, it is one which cannot have stability without the effective functioning of certain normative elements".

2. Esse conceito decorre da análise pragmática da linguagem. A linguagem pode ser analisada a partir de três aspectos. A sintaxe, que estuda a relação entre signos; a semântica que estuda a relação da linguagem com os objetos de significação e, finalmente, a pragmática, que estuda o uso da linguagem entre falantes competentes. Na teoria dos atos de fala, que estuda as condições sob as quais falar é fazer, um ato de fala é composto por três elementos. Um elemento locucionário que se refere ao conteúdo da emissão, o que se diz; um elemento ilocucinário, que se relaciona a oferta de um vínculo através de uma emissão de um falante a um ouvinte, uma promessa, uma ordem, etc., um fazer dizendo algo; e o elemento perlocucionário que se refere aos efeitos intencionais da emissão sobre um ouvinte, ou causar um efeito mediante um fazer dizendo algo (TAC, I, p. 370-1).

3. Importa referir aqui que Habermas distingue, ainda, entre ação estratégica e ação instrumental. Há uma distinção entre estas duas formas de ação, grosso modo pode-se dizer que na primeira há interação, na segunda não. Ver: HABERMAS, Jürgen. Lecciones sobre una Fundamentación de la Sociología en Términos de Teoría del Lenguaje. In: Teoría de la Acción Comunicativa: complementos e estudios previos. Catedra, Madri, 1997.

\section{REFERÊNCIAS}

ALEXY, Robert. Teoria de los Derechos Fundamentales. Madrid: Centro de Estudios Constitucionales, 1993

ARATO, Andrew; ROSENFELD, Michel. Habermas on Law and Democracy: Critical Exchanges. Los Angeles: UCP, 1998.

BAXTER, Hugh. Habermas: the discourse theory of law and democracy. Stanford University Press. California: Stanford, 2011.

COELHO, André. Explicando "Direito e Democracia" (4B-I): A Tensão entre Facticidade e Validade no Interior da Linguagem. In: COELHO, André. Filósofo Grego. [S. I.]: 07 jul. 2014. Disponível em: http:// aquitemfilosofiasim.blogspot.com.br/2014/07/explicando-direito-e-democracia-4b-i.html.

DWORKIN, Ronald. Levando os Direitos a Sério. Tradução de Nelson Boeira. São Paulo: Martins Fontes, 2002.

EDGAR, Andrew. Habermas: The Key Concepts. Routledge. New York: London, 2006.

GUNTHER, Klaus. Uma concepção normativa de coerência para uma teoria discursiva da argumentação 
jurídica. Cadernos de Filosofia Alemã 6, p. 85-102, 2000.

HABERMAS, Jürgen. Direito e Democracia: entre facticidade e validade, I e II. Tradução de Flávio Beno Siebeneichler. Rio de Janeiro: Tempo Brasileiro, 1997.

HABERMAS, Jürgen. Between Facts and Norms: Contributions to a Discourse Theory of Law and Democracy. Translated by William Rehg. Cambridge, Massachusetts: The MIT Press, 1996.

HABERMAS, Jürgen. Aclaraciones a la Ética Del Discurso. Tradução de José Mardomingo. Madrid: Editorial Trotta, 2000.

HABERMAS, Jürgen. Teoría de la Acción Comunicativa, I: racionalidad de la acción y racionalización social. Tradução de Manuel Jiménez Redondo. Madrid: Taurus, 2001.

HABERMAS, Jürgen. Teoría de la Acción Comunicativa, II: racionalidad de la acción y racionalización social. Tradução de Manuel Jiménez Redondo. Madrid: Taurus, 2001.

HABERMAS, Jürgen. O Discurso Filosófico da Modernidade: doze lições. Tadução de Luiz Sérgio Repa e Rodnei Nascimento. São Paulo: Martins Fontes, 2002.

HABERMAS, Jürgen. La Inclusión Del Outro: estudios de teoría política. Tradução de Juan Carlos Velasco Arroyo e Gerard Vilar Roca. Barcelona: Editorial Paidós, 2002b.

HABERMAS, Jürgen. Mudança Estrutural da Esfera Pública: investigações quanto uma categoria da sociedade burguesa. Tradução de Flávio R Kothe. Rio de Janeiro: Edições Tempo Brasileiro, 2003.

HABERMAS, Jürgen. Reply to Symposium Participants, Benjamin N. Cardozo School of Law. In: ROSENFELD, Michel; ARATO, Andrew. Habermas on Law and Democracy. Berkeley - Los Angeles London: UCP, 1998, p. 381-452.

HABERMAS, Jürgen; RAWLS, John. Debate sobre el Liberalismo Político. Barcelona: Paidos, 1998.

HABERMAS, Jürgen. Um Perfil Filosófico-Político: entrevista com Jürgen Habermas. Novos Estudos CEBRAP, n. 18, p. 77-102, set. 1987.

McCARTHY, Thomas. La Teoría Crítica de Jürgen Habermas. Tradução de Manuel Jiménez Redondo. Madrid: Editorial Tecnos, 1998.

McCARTHY, Thomas. Kantian Constructivism and Reconstructivism: Rawls and Habermas in dialogue. Ethics, v. 105, n. 1, p. 44-63, out. 1994.

NOBRE, Marcos; REPA, Luiz. Introdução: reconstruindo Habermas: etapas e sentido de um percurso. In: NOBRE, Marcos; REPA, Luiz (org.). Habermas e a Reconstrução. Campinas: Papirus, 2012.

NOBRE, Marcos; TERRA, Ricardo (org.). Direito e Democracia: um guia de leitura de Habermas. São Paulo: Malheiros, 2008.

PARSONS, Talcott. The Structure of Social Action. Glencoe: free press, 1949.

PETERS, Bernhard. On Reconstructive Legal and Political Theory. In: DEFLEM, Mathieu (org.). 
Habermas, Modernity and Law. London: SAGE, 1996. p. 101-34.

REHG, William. Translator's Introduction. In: Between Facts and Norms: Contributions to a Discourse Theory of Law and Democracy. Translated by William Rehg. Cambridge, Massachusetts: The MIT Press, 1996.

REPA, Luiz. A teoria reconstrutiva do direito. Notas sobre a gênese lógica do sistema dos direitos fundamentais em Habermas. Doispontos, Curitiba, São Carlos, v. 7, n. 2, p. 141-156, out. 2010.

REPA, Luiz. Reconstrução da História da Teoria: observações sobre uma procedimento da Teoria da Ação Comunicativa. In: NOBRE, Marcos; REPA, Luiz (org.). Habermas e a Reconstrução. Campinas: Papirus, 2012. p. 43-64.

ROCHA, Jean Paul C. Veiga da. Separação dos Poderes e Democracia Deliberativa. In: NOBRE, Marcos; TERRA, Ricardo (org.). Direito e Democracia: um guia de leitura de Habermas. São Paulo: Malheiros, 2008. p. 173-97.

SILVA, Felipe Gonçalves. A Solidariedade entre Público e Privado. In: NOBRE, Marcos; TERRA, Ricardo (org.). Direito e Democracia: um guia de leitura de Habermas. São Paulo: Malheiros, 2008. p. 91-115.

SILVA, Luís Virgílio Afonso da; MENDES, Conrado Hübner. In: NOBRE, Marcos; TERRA, Ricardo (orgs.). Direito e Democracia: um guia de leitura de Habermas. Malheiros. São Paulo, 2008.

Recebido em: 30/06/2021

Aceito em: 18/08/2021 